Revista Iberoamericana. Vol. LXVI, Núm. 191, Abril-Junio 2000, 419-424

\title{
EL ÚLTIMO DE LOS MOHICANOS: UN CUBANO JUDÍO ${ }^{1}$
}

POR

José KoZER

El nacer y crecer en un lugar implica la prerrogativa natural de quedarse en ese lugar permanentemente. Uno no nace argentino, francés, venezolano o cubano para no permanecer en el territorio lógico de la nación. Sin embargo, esta prerrogativa lógica, natural, por siglos ha sido la excepción que ha marcado al judío.

Esta noción de excepción, por supuesto, está marcada por cierta terminología. No existe condición humana que carezca de términos prejuiciosos, o por lo menos de definiciones que intenten delimitar la condición en términos de lenguaje. El judío, por lo tanto, es definido como el "errante” y el "internacional”; estos términos de valor, estas definiciones que demarcan diferencia, estos términos de dolor y alegría, de la alegría positiva de ver más, de estar en más lugares, de siempre pertenecer poco a poco al más allá, de ser dos y tres a la vez, el judío o algo más, y a la vez, algo nuevo y algo diferente, se convierten a base del prejuicio, en términos despectivos de negación. El judío internacional y el judío errante fueron términos utilizados para definir al judío como el egoísta, el que constantemente quiere acaparar (el judío como banquero, el judío que acapara sólo para sí), reduciendo así a un grupo que vagaba sin querer vagar y que también poseía una alta espiritualidad, una espiritualidad desde arriba y, por lo tanto, una espiritualidad que se mantenía sobre todo.

El judío errante, el judío internacional. ¿Una condición? ¿Un aura? ¿Un sentir real y sobre todo poético? ¿Un ser que está por todas partes y simultáneamente en ninguna? ¿Una soledad impuesta sobre mí (estoy parafraseando a Kafka) y en parte voluntariamente buscada por mí? ¿Por el judío que soy yo? El judío sin nación, cuya nación es el lenguaje, lenguaje del libro y del Libro, el judío cuya nación es Dios, Dios que se tiene que buscar y que recuperar constantemente, se ve expulsado en el desplazamiento, un abandonado del kenoma, el vacío cósmico en el cual ha sido arrojado. Este desplazamiento, esta búsqueda secreta para que Dios desplace el kenoma, para desplazar el vacío cósmico, se ve en uno de mis primeros poemas, que después incluyo en el libro titulado Este judío de números y letras. En este poema, yo descubro para mí, a través de la poetización de un padre, mi padre, mi padre poético, un cierto destino: Yo, el errante; yo, el internacional; una sucesión de

\footnotetext{
${ }^{1}$ Texto leído en la Universidad de California, Irvine, en febrero de 1996. Título original: “The Last of the Mohicans: A Cuban Jew”.
} 
lugares y más lugares, por siempre y por todas partes, y por siempre en ninguna parte excepto en el poema, en el lenguaje del poema, en el libro. Este padre que erra, este padre de padres internacional, este fantasma de padre, que el poema casi no comprende a fondo, fue retratado y narrado en ese poema temprano como el errante y el internacional; el judío emblemático, de la siguiente manera:

TE ACUERDAS, SYLVIA

Te acuerdas, Sylvia, cómo trabajaban las mujeres en casa.

Parecía que papá no hacía nada.

Llevaba las manos a la espalda inclinándose como un rabino fumando una cachimba corta de abedul, las volutas de humo le daban un aire misterioso, comienzo a sospechar que papá tendría algo de asiático.

Quizá fuera un señor de Besarabia que redimió a sus siervos en épocas del Zar, o quizás acostumbraba reposar en los campos de avena y somnoliento a la hora de la criba se sentara encorvado bondadosamente en un sitio húmedo entre los helechos con su antigua casaca algo deshilachada.

Es probable que quedara absorto al descubrir en la estepa una manzana.

Nada sabía del mar.

Seguro se afanaba con la imagen de la espuma y confundía las anémonas y el cielo.

Creo que la llorosa muchedumbre de las hojas de los eucaliptos lo asustaba.

Figúrate qué sintió cuando Rosa Luxemburgo se presentó con un opúsculo entre las manos ante los jueces del Zar.

Tendría que emigrar pobre papá de Odesa a Viena, Roma, Estambul, Quebec, Ottawa, Nueva York.

Llegaría a La Habana como un documento y cinco pasaportes, me lo imagino algo maltrecho del viaje.

Recuerdas, Sylvia, cuando papá llegaba de los almacenes de la calle Muralla y todas las mujeres de la casa Uds. se alborotaban.

Juro que entraba por la puerta de la sala, zapatos de dos tonos, el traje azul a rayas, la corbata de óvalos finita

y parecía que papá no hacía nunca nada.

Hemos llegado, esto es Cuba, y ahora él tiene una nación para sus hijos. Él es de todas partes y de ninguna, pero nosotros, sus hijos, hemos echado raíz, somos parte de una nación, pertenecemos a un lugar y un territorio, atados. El día viene cuando el hijo (zind y yingl) escucha la vocación del espacio y la nación en una lengua diferente, idish y no español, hebreo y no español, y claro comienza a divagar. Él, el hijo, divaga y erra en el lenguaje, por el lenguaje y en un lenguaje que es dos y tres veces a la vez, combinado y mestizo, escrito de derecha a izquierda, y de izquierda a derecha, en el alfabeto fenicio, pero también en el hebreo. Esta duplicidad, este constante multiplicarse del ser a través del lenguaje aparece cualquier día, se presenta como un ritual, y por lo tanto como poesía; un ritual marcado, un ritual diferente, un ritual que no es cubano entre cubanos y en Cuba, un ritual de una minoría que es parte de una minoría errante e internacional que ha sobrevivido a través de los siglos como parte de un ritual más grande, un Dios más grande, solo y bárbado, áspero, difícil de encontrar, incomunicado, el que es accesible sólo a través de la voz, el que se escucha y no 
se ve, y el que sólo se escucha poéticamente. En ese día, Pésaj, Pascua o Passover, el hijo se descubre a sí mismo como parte del padre, el hijo cubano es parte del padre, el judío, el padre, el polaco o Polach, el que proviene de otro polaco, a esta isla tropical donde nunca nieva y en donde hay más negro que blanco, el negro es la comida, hay gente negra, negra como las letras de la tinta de la Biblia, el Libro rechazado por mi padre en contra de su padre, el Libro que ahora preside este día de días, Pésaj, Pascua o Passover, el día que ritualiza la presencia y la errancia del judío a través de la presencia del padre, y el padre del padre:

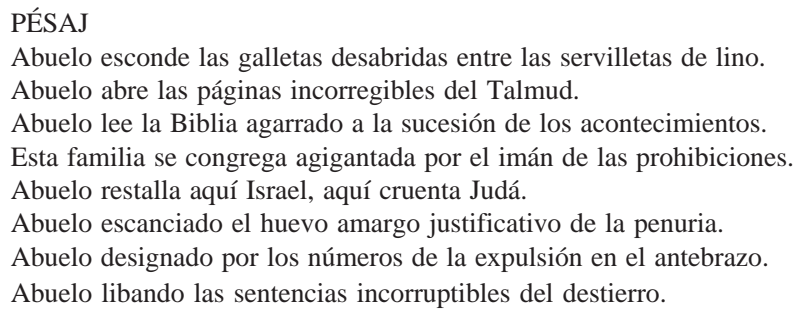

El ritual y el miedo; el miedo y el amor; el amor y el ser; el ser como condición, la doble y múltiple condición del judío que busca la unidad. Vive para el día de días y cuando muere, sea padre, abuelo o hijo, es homenajeado, tal vez por primera vez en su vida, a través de la congregación y el llamado de todos los judíos; esto es, a través de la congregación y el llamado del lenguaje, el lenguaje del ritual y del Libro, para poder finalizar el peregrinaje, un peregrinaje que se da a través del alfabeto y las letras y el lenguaje que está en vía hacia la unidad y la morada final:

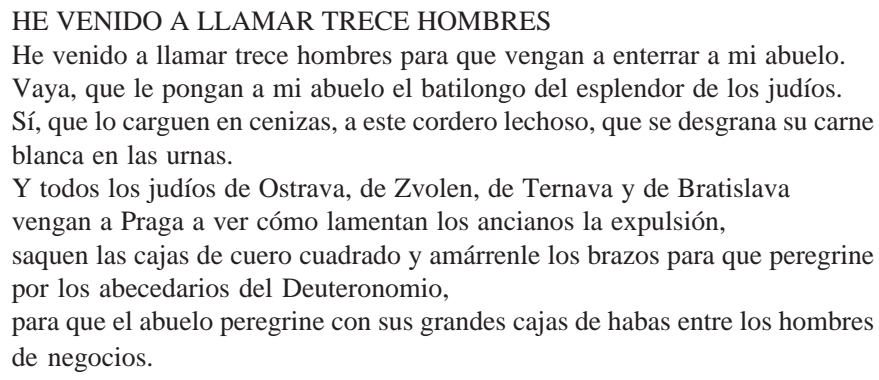

En la vida la comunidad se junta; en la muerte la comunidad se junta. Y cuando se junta, se ve a sí misma como una colectividad judía en términos del lenguaje, un lenguaje adquirido en el shul; el shul es la escuela, el shul es el templo: el shul es la familia, la comunidad, el grupo errante que se contempla a sí mismo, y se pregunta cuándo vendrá el día que tenga respuestas, las respuestas que aparezcan en un lenguaje visible, escuchado y visible: el lugar utópico, una permanencia. Para responder, uno va al shul, para aprender si uno puede postular la pregunta de las preguntas y así poder escuchar y ver la respuesta de las respuestas; la cual, por el momento, se dispersa como palabras, muchas palabras, por todo el libro, a 
través de todas las tierras. Scuola, en latín, implica un lugar reducido, aislado, para poder aprender; la palabra en chino para familia, chia, también quiere decir —al aplicarle una tonalidad diferente- escuela; el shul, la familia, la reclusión, la forma de ser y de grupo, la escuela. El judío entra al shul para saber, para conocer la unidad, y todas las reglas de la unidad, más allá de la errancia y de los lugares, más allá del ritual pero a través del ritual; el lenguaje como templo, el lenguaje que eventualmente se va a satisfacer a sí mismo y se saciará: el hambre saciada de entender, el saber, la sabiduría en contra del kenoma, el vacío:

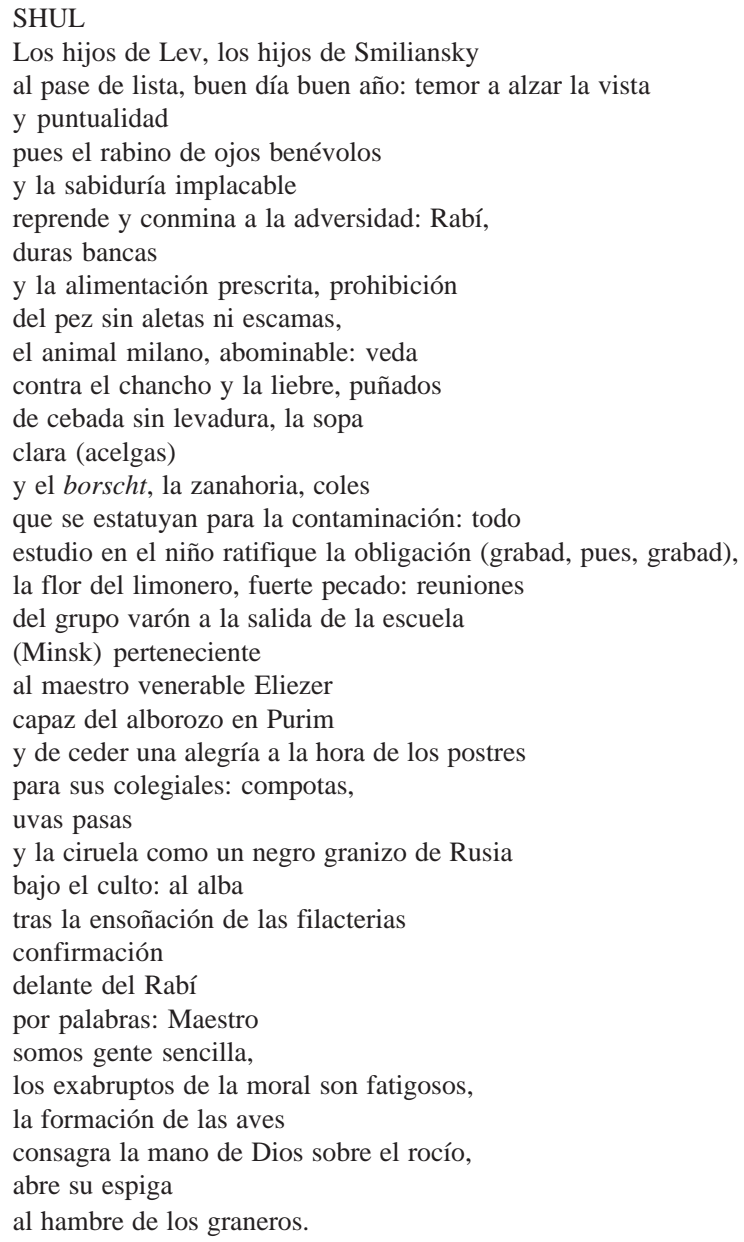

Entonces, no tenemos un lugar, y en vez de lugar tenemos un Libro en contra del errar, el Libro que está hecho de palabras, un lenguaje jeroglífico, cuneiforme y obtuso, un 
lenguaje cabalístico. Cuando el lenguaje sea visible, tendremos un lugar, terrestre y celestial, efímero y permanente, un edén, un jardín, adánico y preadánico, futuro y cancelado. Un Nirvana: un lugar fuera del lenguaje, un lugar nunca más contaminado por el lenguaje y la necesidad del lenguaje.

Mientras tanto, celebramos. Una celebración de la ausencia. La celebración de la multiplicidad, la duplicidad, la triplicidad, la contaminación, el cruce de razas o el mestizaje, la polifonía y el apartamiento, el sentirse extraño y la participación. El hijo celebra lo que emana del padre: celebra en español, en cubano, en caribeño y en idish lo que el padre celebró en idish polaco, en el idish hebreo, ateo o religioso, en el idish ancestral:

\author{
PASCUA EN LA HABANA \\ Éste es el día de la Pascua. \\ Éste es el día en que los judíos se reclinan \\ sobre el día a día de la compra y de la venta, \\ pasan por Beirut, desembarcan en La Habana, \\ éste es el día en que fundan una sinagoga, abren una bodega cubana, \\ y reúnen a todos los nietos de la diáspora, \\ es la hora precisa en que Daniel Santos ameniza acompañado por el Conjunto \\ Casino, \\ Jacobo le regala a María Brull una caja de jabones perfumados, \\ Toña la Negra desempata un ritmo encajonado en la televisión, \\ los judíos ratifican las actas de la alianza, \\ los judíos se recogen a llorar las ausencias del agua, \\ se encogen miserablemente agarrados a las cuatro patas de la mesa de los panes, \\ mastican el pan de las proposiciones por los cuatro confines de la tierra \\ lamentando el éxodo inclemente de las prohibiciones, \\ escuchando atentamente la voz de los abuelos de Aarón y Yahveh, \\ esa cólera de la montaña que nos hace ricos y nos hace indigentes, \\ y ojo por ojo, diente por diente, \\ los judíos ratifican día a día la tremenda expiación de los hijos de Israel \\ que pagan cinco veces más, toro por toro, \\ mieses por mieses, y animal vacuno por animal vacuno, \\ padres por padres resarciendo irremisiblemente la ley de los decálogos.
}

Y después, la celebración acaba. Tiene que terminar; tiene que terminar puesto que somos judíos, errantes e internacionales (como se nos ha llamado). La ironía de la historia es que el nombre que se nos ha dado también describe al que nos nombró: el cubano (y obviamente utilizo este término simbólicamente) que me nombró errante, una figura internacional que simboliza el desarraigo y el desplazamiento, es ahora un errante, un judío desplazado y diaspórico, un cubano judío, hijo y padre desplazado de la tierra y del edén, desplazado hacia el jardín seco de la rica multiplicidad y pluralidad; porque todos los cubanos ahora son judíos, ahora todos somos judíos, en un estado de flujo y cambio y migración, dolorosamente mudándonos de una cosa a otra, agonizados por las fuerzas históricas, agonizados por un Dios poderoso que dice un algo específico que escuchamos pero todavía no podemos descifrar. Y así, cubano o judío, el judío cubano o el cubano judío, estamos condenados al lenguaje, y a celebrar la Diáspora: 


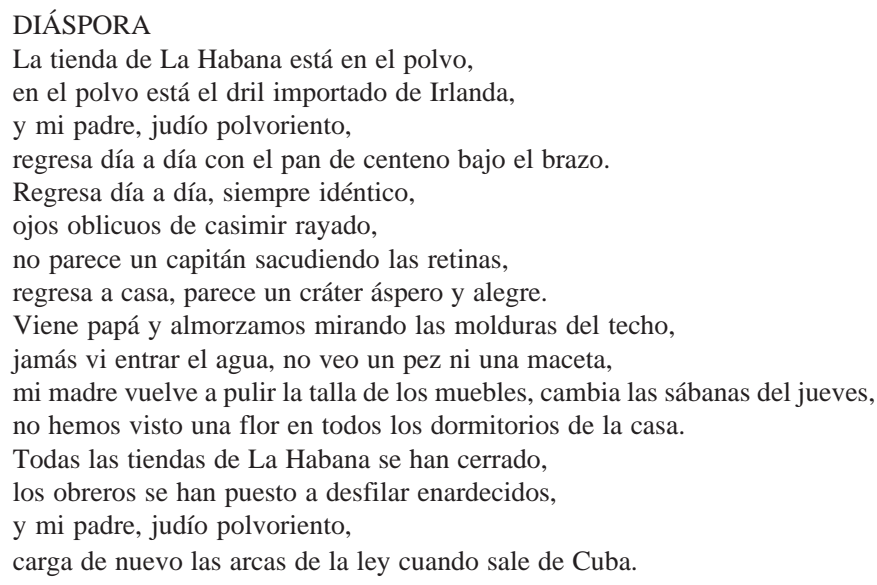

Fin del cuento. Aquí el cuento tiene que parar. Todo tiene que parar, y las vasijas están rotas. Termina, en la aproximación, a base de un símbolo; una palabra dividida, pero que espera la reunión. Yo nací en La Habana, Cuba, el 28 de marzo de 1940, y en la misma fecha, una judía sefardita nació en Ávila, España, el 28 de marzo de 1515. Santa Teresa de Jesús se convirtió, pero nunca dejó de ser judía: Yo, el cubano, nunca dejé de ser judío aunque haya nacido (en efecto, una forma de conversión) cubano.

La ironía de mi destino es que yo nací cubano, de padres judíos provenientes de Polonia y Checoslovaquia (una palabra que nunca puedo escribir en inglés ${ }^{2}$ sin consultar el diccionario, esta pseudo Biblia que a veces parece ser la Biblia de Biblias, la única Biblia posible; la Biblia de Babel): a la edad de 20 yo dejé mi país, por razones políticas y apolíticas. Nunca he regresado, nunca regresaré mientras viva. Mis hijas nacieron en los Estados Unidos; son norteamericanas, no cubanas. Y así, yo fui la primera y última generación cubana. Un verdadero judío. Tal vez un verdadero nuevo cubano, un verdadero ciudadano de la nación errante e internacional que mejor se puede definir como mohicano, el último de los mohicanos, yo, un judío mohicano.

Traducción de Saúl Jiménez Sandoval

\footnotetext{
${ }^{2}$ N. del E. En la versión original de este ensayo, Kozer escribe "Checoslovaquia” (en español). La palabra en inglés se escribe "Czechoslovakia".
} 